\title{
A percepção dos gestores sobre os objetivos do esporte nos municípios
}

\section{The perception of managers about the objectives of sports in municipalities}

\section{La percepción de los gestores sobre los objetivos del deporte en los municipios}

\author{
Santos, Marco Aurélio Gonçalves Nóbrega ${ }^{1,2}$; Freire, Elisabete dos Santos ${ }^{1}$; Bastos, Flávia da Cunha ${ }^{3}$; \\ Mazzei, Leandro Carlos ${ }^{4}$ \\ ${ }^{1}$ Universidade São Judas Tadeu, ${ }^{2}$ Faculdade Estácio de Sá de Ourinhos; ${ }^{3}$ Universidade de São Paulo, \\ ${ }^{4}$ Universidade Estadual de Campinas
}

\section{RESUMO}

O presente estudo teve como objetivos caracterizar o perfil dos gestores municipais de esporte de cidades pertencentes a um consórcio intermunicipal no estado de São Paulo e conhecer seu olhar sobre os objetivos do esporte no município. Foi realizada uma pesquisa qualitativa, com a participação de 12 gestores de esporte pertencentes à União dos municípios da Média Sorocabana do Estado de São Paulo (UMMES). Foram realizadas entrevistas semiestruturadas, gravadas e áudio e transcritas. Para análise dessas entrevistas foi utilizada a técnica de Análise de Conteúdo. Foi possível verificar que o perfil dos gestores esportivos municipais se assemelha ao identificado em outros estudos realizados. Também se constata a existência de uma cultura que desconsidera as competências e habilidades necessárias para o gerenciamento esportivo inerente às organizações esportivas. Em suas entrevistas, os gestores declaram que o esporte em seus municípios tem como objetivos contribuir para a inclusão social, melhorar a saúde e a qualidade de vida dos praticantes, identificar novos talentos para o esporte e democratizar o acesso às práticas esportivas. Percebemos que parte dos objetivos propostos não podem ser atingidos apenas com a prática do esporte, mas que dependem da elaboração de uma política pública que integre diferentes secretarias municipais..

Palavras chave: Gestão do Esporte; Consórcio Intermunicipal; Significado do Esporte.

\section{ABSTRACT}

The purpose of this inventory was to characterize the profile of sports managers from cities belonging to an intermunicipal consortium in the state of São Paulo and to know their view on the objectives of the sport in the city. A qualitative research was carried out, with the participation of 12 sports managers belonging to the Union of the municipalities of Media Sorocabana, in São Paulo. Semi-structured, recorded and audio and transcribed interviews were performed. For the analysis of these interviews, the Content Analysis technique was used. It was possible to verify that the profile of the municipal sports managers is similar to that identified in other studies. Also it is verified the existence of a culture that disregards the professional skills and abilities for the sport management, inherent to the sport organizations. In their interviews, managers claim that sport in their cities aims to contribute to social inclusion, improve health and quality of life, identify new talent for sports and democratize access to sports practices. We realize that some of the proposed objectives cannot be achieved only with the practice of sports, but that they depend on the elaboration of a public policy that integrates different municipal secretariats.

Keywords: Sports Management; Intermunicipal Consortium; Meaning of Sport 


\section{Santos, M.; Freire, E.; Bastos, F.; Mazzei, L.}

\section{RESUMEN}

El presente estudio tuvo como objetivos caracterizar el perfil de los gestores del deporte, en ciudades que constituyen un consorcio intermunicipal de São Paulo y conocer su mirada sobre los objetivos del deporte en la ciudad. Se realizó una investigación cualitativa, con la participación de 12 gestores de deporte pertenecientes a la Unión de los municipios de la Media Sorocabana del Estado de São Paulo (UMMES). Se realizaron entrevistas semiestructuradas, grabadas y audio y transcritas. Para el análisis de estas entrevistas se utilizó la técnica de Análisis de Contenido. Fue posible verificar que el perfil de los gestores deportivos municipales se asemeja al identificado en otros estudios realizados. También se constata la existencia de una cultura que desconsidera las competencias y habilidades necesarias para el manejo deportivo inherente a las organizaciones deportivas. En sus entrevistas, los gestores declaran que el deporte tiene como objetivos contribuir a la inclusión social, mejorar la salud y la calidad de vida de los practicantes, identificar nuevos talentos para el deporte y democratizar el acceso a las prácticas deportivas. Se percibe que parte de los objetivos propuestos no pueden ser alcanzados sólo con la práctica del deporte, sino que dependen de la elaboración de una política pública que integre diferentes secretarías municipales.

Palabras clave: Gestión del deporte; Consorcio Intermunicipal; Objetivos del Deporte;

\section{INTRODUÇÃO}

A gestão do esporte pode ser considerada um conjunto de ações que acontecem no interior das organizações esportivas, com o objetivo de tornar mais efetiva, em termos administrativos, a promoção do esporte em suas diferentes manifestações, serviços e produtos, visando atender os interesses e necessidades de diferentes grupos (Rocha \& Bastos, 2011; Mazzei \& Bastos, 2012; Chelladurai, 2013; Parks, Quaterman \& Thibault, 2007). Mazzei e Rocco Junior (2017) definem a gestão do esporte como o gerenciamento de diversas atividades e organizações nas quais o esporte está envolvido. A gestão do esporte contempla conhecimento, visão e tomada de decisão para planejar, elaborar e avaliar, tanto as organizações como as atividades esportivas que são gerenciadas, sendo que para que isso aconteça, de maneira efetiva, é recomendável conhecer a realidade em questão, no caso, as características e particularidades de atividades e serviços esportivos.

Em cenário no qual a sociedade está mais exigente em relação à qualidade das organizações e à prestação de serviços, a gestão do esporte tem papel fundamental, visando à otimização dos recursos materiais, humanos e econômicos para o alcance dos objetivos estipulados e satisfação de todos os interessados. Assim, a preparação profissional do gestor do esporte passa a ser cada vez mais relevante. Chelladurai (2013) afirma que, para a formação de um gestor esportivo, é imprescindível que existam conceitos e práticas sobre organização e coordenação das atividades em seus diversos meios de intervenção, o que também envolve o conhecimento sobre instalações esportivas, eventos, recursos humanos, relações públicas, leis, marketing e administração financeira, independente da instituição em que irão atuar.

No Brasil, se conhece pouco sobre quem é o gestor e qual sua forma de olhar para o esporte. Estudos recentes revelam que existe uma maior participação masculina, que a formação não é bem definida e que é comum a presença de pessoas vindas das mais diversas áreas, que acabam escolhidas tendo como requisito desde o seu passado esportivo ou por influência político-partidária (Amaral \& Bastos, 2015).

No entanto, apesar da existência de alguns estudos recentes, raros são aqueles que analisam o contexto da gestão municipal do esporte. Os programas e projetos desenvolvidos pelos municípios desempenham papel fundamental para que a população brasileira tenha acesso ao esporte, garantia estabelecida na Constituição do país. Nessa medida, o gestor deve ser o principal articulador do esporte no município (Gómez Tafalla \&Mestre Sancho, 2005).

Diante disso, para que as organizações esportivas municipais tenham condições de melhorar a organização e coordenação do esporte com os projetos, programas e atividades, exige-se mais competência do gestor municipal de esporte. Ele é o responsável direto por essa organização e toma decisões com base em suas concepções e percepções. Concordando com Amaral (2015), acreditamos que conhecer o gestor do esporte e seu olhar sobre o 


\section{Percepção dos gestores no esporte municipal}

esporte municipal pode contribuir para o processo de gestão, promovendo maior debate sobre o tema e sobre os rumos do esporte brasileiro.

A partir deste quadro, elaboramos o presente estudo com os objetivos de: (1) caracterizar o perfil dos gestores municipais de esporte de doze cidades pertencentes a um consórcio intermunicipal no estado de São Paulo e (2) conhecer seu olhar sobre os objetivos do esporte no município. Ressaltamos que a compreensão das características e percepções dos gestores municipais pode servir de indicativo para melhor elucidar a importância do gestor e a contribuição para a gestão do esporte no país.

\section{MÉTODO}

Realizamos um estudo qualitativo, com a participação de 12 gestores de esporte de municípios na microrregião de Ourinhos (SP), pertencentes à União dos municípios da Média Sorocabana do Estado de São Paulo (UMMES). A UMMES atua como um consórcio intermunicipal, constituído em 1994, com o objetivo de implementar políticas públicas articuladas entre os municípios da região mencionada, focalizando diferentes áreas, como a saúde, o esporte e a cultura.

\section{Participantes}

Participam do Consórcio 13 municípios: Bernardino de Campos (10.776 habitantes); Canitar (4.369 habitantes); Chavantes (12.437 habitantes); Espírito Santo do Turvo (4244 habitantes); Ibirarema (6.725 habitantes); Ipaussu (13.663 habitantes); Óleo (2.673 habitantes); Ourinhos (103.035 habitantes); Ribeirão do Sul (4.446 habitantes); Salto Grande (8.787 habitantes); São Pedro do Turvo (7.198 habitantes); Santa Cruz do Rio Pardo (43.921 habitantes) e Timburi (2.646 habitantes) (IBGE, 2010). Com exceção de Ourinhos e Santa Cruz do Rio Pardo, os demais municípios não possuem mais que 15 mil habitantes. Apenas um dos gestores desses municípios optou por não participar da pesquisa, por estar em tratamento médico durante o período em que ela foi realizada.

\section{Instrumentos}

Para identificar as características dos gestores e seu olhar sobre o papel do esporte no município utilizamos a entrevista semiestruturada (Minayo, 2008), com o apoio um roteiro com questões sobre o perfil dos gestores (gênero, idade, tipo de vínculo, tempo de atuação no cargo, formação acadêmica e atuação profissional fora da gestão pública) e sobre suas percepções e perspectivas sobre o papel do esporte no município em que faz a gestão do esporte.

\section{Procedimentos}

Antes de iniciar a pesquisa, os participantes foram informados sobre os objetivos e procedimentos do estudo e, para registrar sua concordância, assinaram o Termo de Consentimento Livre e Esclarecido. As entrevistas foram realizadas individualmente, em local e horário definidos em comum acordo entre entrevistados e entrevistador, tendo uma duração média de 35 minutos. O áudio de cada entrevista foi registrado em gravador de voz e sua a transcrição foi realizada para possibilitar a análise. Todos os procedimentos desta pesquisa foram aprovados pelo Comitê de Ética em Pesquisa da Universidade São Judas Tadeu, conforme parecer no 1.347827/ 2015.

\section{Análise}

A análise das informações obtidas foi realizada por meio da análise de conteúdo seguindo os três passos propostos por Campos (2004): leitura flutuante, seleção das unidades de análise e categorização. Procuramos construir o sistema de codificação, a partir de categorias de análise definidas a posteriori.

\section{RESULTADOS E DISCUSSÃO}

Após análise das entrevistas, identificamos as características dos gestores participantes, que foram sintetizadas no quadro 1.

Quadro 1: Caracterização dos gestores municipais

\begin{tabular}{|c|c|c|c|c|}
\hline Gestor & Sexo & Idade & Formação & $\begin{array}{c}\text { Tempo } \\
\text { No cargo }\end{array}$ \\
\hline G1 & M & 28 & Educação Física & 3,10 anos \\
\hline G2 & M & 34 & Educação Física & 3,10 anos \\
\hline G3 & M & 51 & Educação Física & 3,10 anos \\
\hline G4 & F & 36 & Educação Física & 5 anos \\
\hline
\end{tabular}


Santos, M.; Freire, E.; Bastos, F.; Mazzei, L.

\begin{tabular}{|c|c|c|l|l|}
\hline G5 & M & 62 & $\begin{array}{l}\text { 2o Grau } \\
\text { Completo }\end{array}$ & 2,10 anos \\
\hline G6 & $\mathrm{M}$ & 49 & Educação Física & 8 anos \\
\hline G7 & $\mathrm{F}$ & 30 & Educação Física & 3,10 anos \\
\hline G8 & $\mathrm{M}$ & 47 & Educação Física & 6,10 anos \\
\hline G9 & $\mathrm{M}$ & 38 & Educação Física & 06 anos \\
\hline G10 & $\mathrm{M}$ & 47 & Educação Física & 11 anos \\
\hline G11 & $\mathrm{M}$ & 29 & $\begin{array}{l}\text { Ciências } \\
\text { Biológicas }\end{array}$ & 3,10 anos \\
\hline G12 & $\mathrm{M}$ & 36 & Direito & 12 anos \\
\hline
\end{tabular}

Fonte: Elaborado pelo autor (2017)

Em relação ao gênero, pudemos identificar que dos 12 gestores, 10 são do sexo masculino, o que corresponde a $83,3 \%$ dos participantes. Esta predominância do sexo masculino confirma resultados já apresentados na literatura e pode ser percebida nos diversos segmentos e organizações esportivas públicas. Karnas (2013) analisou o perfil de 169 gestores de esporte de municípios do Rio Grande do Sul e verificou que apenas $17 \%$ eram mulheres. Infelizmente, a existência de diferentes oportunidades para homens e mulheres se manifesta em diferentes setores da sociedade e do esporte. Entre os gestores, essa desigualdade de gênero é ainda mais evidente, como já explicitam vários autores, entre eles Amaral e Bastos (2015) e Anchieta (2010). Entretanto, os estudos de realizados por Valente (2011) e Carvalho e Cruz (2007) indicam que algumas mudanças estão ocorrendo.

A faixa etária média dos gestores participantes foi de 36,6 anos, demonstrando que os gestores da UMMES apresentam uma média de idade um pouco menor que a encontrada em outros estudos, como Anchieta (2010), Costa e Sarmento (2012) e Costa et al. (2011). É possível que essa menor média de idade, identificada entre os gestores dos municípios que constituem a UMMES, sinalize para uma tendência específica da gestão esportiva municipal, tendência esta já identificada por Karnas (2013).
Mesmo com uma média de idade mais baixa que a apontada na literatura, não houve diferença em relação ao tempo de experiência dos participantes, quando comparado com os resultados obtidos em outros estudos. Assim, verificamos que apenas dois dos entrevistados, atuam há mais de 11 anos na gestão pública do esporte. Os demais têm entre três e oito anos, confirmando dados encontrados por Anchieta (2010).

Antes de atuarem na gestão pública, diferentes atividades profissionais foram exercidas. Seis deles ocuparam, cargos no setor do comércio, tais como proprietário de academia, gerente de posto de gasolina, comerciante, gerente de loja, bancário. Outros quatro gestores atuaram na área de Educação Física desde o início de suas carreiras profissionais, correspondendo a $33,3 \%$ e ainda tivemos um dos gestores que atuou na área da saúde como Técnico em Laboratório o que correspondeu a 8,3\%.

Verificamos que os participantes não desempenham outra atividade profissional, além da gestão de secretaria ou departamento de esporte em cada município. De modo semelhante, Bastos et al. (2006) constataram que $71,43 \%$ dos gestores investigados não exerciam outra atividade além da gestão. Mas, resultados diferentes foram obtidos por Anchieta (2010), Costa et al. (2011) e Valente (2011). Nesses estudos, a maior parte dos gestores exercia a função concomitantemente com outras atividades profissionais.

Quanto ao regime de contratação dos gestores, verificamos que sete deles ocupam cargos comissionados, enquanto os outros cinco são funcionários efetivos no serviço público municipal, que assumiram cargos na gestão. Esse panorama pode estar relacionado ao fato dos cargos de secretário, diretor e coordenador serem ocupadas por pessoas indicadas pelo poder executivo municipal, como verificaram Linhales et al. (2008). Na organização política brasileira, por vezes os cargos de confiança podem ser utilizados como recurso para a constituição de uma base de apoio para o governante, processo que nem sempre leva em consideração a competência do gestor indicado (Menezes, 2009; Amaral \& Bastos, 2016). Além disso, este processo de negociação política por vezes pode gerar a descontinuidade na implementação de programas e projetos na área do esporte, uma vez que mudanças na administração, em 


\section{Percepção dos gestores no esporte municipal}

razão de eleições ou de reorientação nos cargos são frequentes (Menezes, 2009; Starepravo, 2011; Valente, 2011; Karnas, 2013).

Quanto à formação profissional dos gestores entrevistados, identificamos que um deles não cursou ensino superior, um é graduado em Ciências Biológicas e um terceiro em Direito. Os outros nove participantes são graduados em Educação Física, o que corresponde a $75 \%$ dos participantes. Outros estudos (Zanatta et. al., 2018; Amaral, 2014; Cárdenas, 2013; Valente, 2011) encontraram resultados semelhantes, constatando que a maioria dos gestores de esporte são graduados em Educação Física.

Para Cárdenas e Feuerschütte (2014), a graduação em Educação Física pode ter papel relevante na formação do gestor do esporte, quando a atuação nesta área de intervenção é uma das competências que constituem o perfil profissional definido no Projeto Pedagógico da maioria dos Cursos existentes nesta área. Ainda assim, concordando com Pires e Sarmento (2001), os autores reconhecem que a capacitação do gestor do esporte não pode se limitar aos conhecimentos advindos da formação tradicional em Educação Física.

\section{OBJETIVOS DO ESPORTE MUNICIPAL: O OLHAR DOS GESTORES}

O planejamento na gestão do esporte, quando elaborado, continua sendo responsabilidade exclusiva do gestor e, em alguns casos, da equipe de profissionais que atua junto dele. Dessa forma, conhecer melhor os objetivos que têm orientado a gestão do esporte é fundamental, já que eles definem $\mathrm{o}$ planejamento e as atividades implementadas. A partir da análise de conteúdo das entrevistas, identificamos que os objetivos declarados pelos gestores podem ser classificados em quatro categorias: Esporte e Inclusão Social; Esporte, saúde e qualidade de vida; Esporte e Formação de Talentos; e Esporte e Democratização.

A categoria Esporte e Inclusão Social reúne declarações dos gestores que consideram um dos principais objetivos do esporte municipal a inclusão social de crianças e adolescentes, contribuindo para seu desenvolvimento social. Para esses gestores, o esporte é uma forma de ocupar o tempo de crianças e jovens, para que não se envolvam com o uso de drogas e com a criminalidade. Destacamos alguns trechos das entrevistas realizadas, nos quais se identifica esta percepção:

\begin{abstract}
O principal objetivo do esporte é trabalhar nos projetos sociais: a criança, o adolescente e o jovem. Porque essa é a fase para melhor se trabalhar; para tirar as crianças e os jovens da rua, de forma a passar para eles a responsabilidade, recuperar a autoestima, viver no coletivo. (G5)
\end{abstract}

Deve ser voltada para tirar as crianças da rua, para que a criança não siga um mal caminho [...] Então, nós temos que fazer projetos que tirem a criança da rua. [...] aprender o esporte de modo em geral, que seria a inclusão social..[...] Para que a criança não siga um mal caminho, as drogas. (G6)

Então, entendo que o principal objetivo aqui hoje deve estar voltado para a inclusão social e para a qualidade de vida das pessoas.......] Pois se elas estiverem dentro do esporte elas estarão fora das drogas. (G11)

As políticas públicas construídas nas últimas décadas têm valorizado o esporte como recurso para estimular a inclusão social e, possivelmente, influenciem o discurso dos gestores entrevistados. Como explica Starepravo (2011), com a promulgação da Constituição Federal, em 1988, o esporte passou a ser considerado como um direito social. Em 2003, foi criado o Ministério do Esporte (ME), responsável por construir a Política Nacional de Esporte (PNE), que visa, além do estímulo ao esporte de rendimento, o desenvolvimento de ações de inclusão social que garantam o acesso à prática esportiva, à qualidade de vida e ao desenvolvimento humano.

Os relatos dos gestores evidenciam o desejo de concretizar as políticas públicas defendidas nacionalmente. Entretanto, as crenças expressas pelos entrevistados demonstram certa ingenuidade, atribuindo ao esporte o poder de, isoladamente, contribuir para a solução de graves problemas sociais. Como ressaltam Vianna e Lovisolo (2011) e Theodoulides e Armour (2001) os benefícios da prática esportiva para a desenvolvimento social têm sido proclamados há muito tempo. Lopes et al. (2007), ao analisarem dirigentes municipais de esporte e lazer em 13 municípios da Grande BH identificaram que sete deles também consideram a inclusão social como um dos objetivos principais de suas gestões. Resultados semelhantes foram obtidos por Menezes (2009) e Brust, Baggio e Saldanha Filho (2006). 


\section{Santos, M.; Freire, E.; Bastos, F.; Mazzei, L.}

Para Lopes et al. (2007), este discurso pode estar fundamentado em concepção assistencialista e paternalista do esporte. Veronez (2005), por sua vez, argumenta que o esporte é utilizado de forma e populista, ao se justificar como uma ferramenta de enfrentamento, redução e eliminação de problemas sociais. Com frequência, os programas implementados carecem de um planejamento estruturado e de gestores que compreendam as políticas públicas do nacionais de Esporte. De acordo com Bahia e Lima (2011), a inclusão social e a democratização do acesso ao esporte dependem de uma análise crítica da realidade social, que considere o contexto socioeconômico, os comportamentos, os valores $\mathrm{e}$ as relações que favorecem a exclusão de alguns grupos (negros, idosos, homossexuais, mulheres, deficientes entre outros).

Embora a inclusão social apareça como um objetivo no discurso dos gestores, alguns estudos têm comprovado que políticas públicas implementadas não conseguem atingir este objetivo. Silva (2012), ao estudar a concepção de esporte e lazer na secretaria estadual de esporte e lazer no Espírito Santo, constatou que as políticas públicas de esporte não buscaram garantir o acesso ao esporte, como um direito, já que suas ações priorizam o esporte de rendimento. Da Mata (2011) avaliou as políticas públicas de esporte e lazer de João Pessoa/PB e concluiu que se pautam em ideais neoliberais, que favorecem a lógica do mercado em detrimento das necessidades da sociedade. Assim, as políticas públicas de esporte parecem não dar a devida importância ao esporte e ao lazer para as camadas mais carentes da população e não contribuem para a democratização e universalização do esporte.

Ao contrário dos resultados apresentados por Silva (2012) e Da Mata (2011), na percepção da maior parte dos profissionais aqui entrevistados, a gestão do esporte implementada em seus municípios tem contribuído para a inclusão social do público atendido. G3 é uma exceção entre seus pares e argumenta que, embora seu objetivo seja a inclusão social, o município não tem contribuído para que ele seja atingido. Para este gestor, além das dificuldades financeiras enfrentadas pela prefeitura, falta uma melhor articulação entre as diferentes secretarias. Nesse sentido, G3 afirma que o trabalho realizado teria que unir:
[...] uma secretaria de ação social; uma secretaria de educação. $O$ esporte pode ser trabalhado dentro das escolas; pode ser trabalhado dentro das praças esportivas; pode ser trabalhado em vários setores. Junto com a cultura também, pois todos esses setores eu acho que têm a ver com o social.

Assim, G3 destaca um aspecto fundamental da gestão pública na atualidade: a intersetorialidade. Neves et al. (2009), ao analisarem a implantação de um programa de atividades esportivas como projeto social, concluíram que esses projetos não podem ser realizados de forma isolada. Em consonância com esta ideia, Silva (2012) enfatiza a necessidade de que sejam adotadas ações intersetoriais. $\mathrm{O}$ autor explica que a intersetorialidade tem por objetivo

[...] o desenvolvimento social por meio da articulação
de saberes entre os cidadãos e instituições públicas e
privadas num processo de cogestão. A
intersetorialidade é a articulação de saberes e
experiências no planejamento, execução e avaliação de
ações politicas, visando o desenvolvimento da
sociedade e inclusão social. (SILVA, 2012,p.91)

Além de G3, G11 também reconhece a relevância da intersetorialidade e declara que vem trabalhando nesta perspectiva:

[...] a secretaria de esporte trabalha com todas as secretarias juntas, trabalha com a educação, trabalha com o bem estar, trabalha com a saúde...então o gestor tem que ter um olhar amplo, porque o futuro do esporte é o futuro de nossas crianças (G11)

A contribuição do esporte para a inclusão social depende de políticas que cumpram os direitos sociais com senso de justiça de forma a reconhecer que existem barreiras, diferenças sociais e econômicas entre indivíduos e grupos, cabendo aos gestores oportunizar, ampliar e diversificar as ações de acesso e democratização da prática esportiva. Entendemos que o esporte deve ser considerado em toda a sua abrangência social, como uma questão de Estado, com secretarias e departamentos que planejem ações articuladas e integradas, para que essas atividades esportivas e de lazer se construam como meios viáveis de acesso e democratização de suas práticas. 


\section{Percepção dos gestores no esporte municipal}

Uma segunda categoria identificada no discurso dos gestores foi denominada Esporte, promoção da saúde e qualidade de vida, reunindo declarações nas quais se considera que uma das principais contribuições do esporte é melhorar da qualidade de vida ou a saúde dos munícipes atendidos. Destacamos a seguir alguns trechos das entrevistas que exemplificam esta categoria:

[..] é levar a prática da atividade física para as pessoas.... gente sabe que o esporte contribui muito com a qualidade de vida e a saúde da pessoa. (G1)

A gente tendo os projetos de esporte na cidade...é uma visão de futuro, essa criança que hoje pratica um esporte e vai crescer um adulto mais sadio. (G7)

Abrangendo todos - crianças, adolescentes, jovens, adultos e idosos - uma forma de elevar a qualidade de vida. (G11)

Segundo DaCosta (2005), nos últimos anos têm sido mais frequentes campanhas de estímulo à prática esportiva, que visem promover e mobilizar a população para adoção de um estilo de vida mais ativo e, consequentemente, a promoção da saúde, da qualidade de vida e do bem estar. Os responsáveis pela gestão do esporte nos municípios assumem também o papel de criar programas e projetos com tal finalidade. Porém, é preciso ressaltar que diante da complexidade envolvida na relação entre esporte, saúde e qualidade de vida, faz-se necessário saber quais são efetivamente as ações, dentro de uma gestão de política pública do esporte, que melhor poderão promover e desenvolver o esporte nessas perspectivas.

Segundo Valente (2011), as ações para a promoção da saúde, que se efetivam no denominado esporte participação, têm sido insuficientes para atender a população. Ações com esta finalidade não têm sido priorizadas pelas políticas públicas, quer seja a nível federal, estadual ou municipal. Com frequência, elas se configuram apenas em promessas que não se concretizam. De acordo com Silva e colaboradores (2013), para o esporte se configurar como estratégia na promoção da saúde e da qualidade de vida se faz necessário refletir acerca de uma ação ampla, considerando os contextos que envolvem a maioria da sociedade.
Shintani (2014), ao estudar entidades esportivas em municípios da região metropolitana de São Paulo, verificou que a promoção da saúde é um objetivo no município de São Bernardo do Campo, onde são desenvolvidas ações pela Secretaria de Esportes, com a implementação de programas intersetoriais e de forma descentralizada, em vinte regiões do município. São ofertadas atividades para pessoas de diferentes faixas etárias. Já no município de São Caetano do Sul são realizadas ações voltadas para a comunidade, direcionadas para o desenvolvimento da cidadania, com a adoção do esporte como meio de educação, saúde e cultura.

Souza (2014) e Catarino (2010) encontraram em seus estudos que as políticas públicas municipais de esporte eram direcionadas ao esporte participação, visando o lazer, a saúde e a qualidade de vida, enquanto Costa (2011) constatou que as mesmas políticas não acontecem na sua totalidade, o que compromete a garantia de acesso e participação no esporte como um direito.

No entanto, o esporte é um fenômeno complexo, com vários significados e sentidos (Marchi Jr., 2015; Tubino, 2010). Por isso, pode ser implementado para atender às várias necessidades e interesses. Para que construir ações esportivas que promovam saúde é preciso que se conheça os seus múltiplos significados, as suas diferentes manifestações, os diferentes cenários da saúde da população em questão, os tipos de atividades esportivas a serem ofertadas, entre outros fatores (Almeida, Gutierrez \& Marques, 2012). Para tal, entendemos que o esporte precisa de uma gestão integrada e inovadora, que busque o envolvimento da sociedade, do poder público em suas diferentes esferas, do setor privado e que seja somado a uma formação dos seus gestores, com conhecimento amplo das concepções de esporte.

Almeida e Gutierrez (2013) ressaltam que não basta investir nas instituições e implantar projetos de esporte para contribuir para a promoção da saúde da população. Isso, segundo o autor é uma perspectiva ingênua de compreensão. É preciso, conhecer e produzir conhecimentos que contribuam, de fato, para as políticas públicas de esporte, que atendam os interesses da sociedade. É preciso conhecer as formas de agir, as metodologias e as boas práticas que estejam ao alcance dos profissionais que irão realizar essas ações. 


\section{Santos, M.; Freire, E.; Bastos, F.; Mazzei, L.}

A formação de talentos para o esporte foi mencionada com um objetivo por dois gestores, constituindo a categoria aqui denominada Esporte e Formação de Talentos. G1 considera que a preparação de talentos para esporte de alto rendimento é um de seus objetivos. Entretanto, ele declara que este objetivo está em segundo plano, sendo prioridade a inclusão social e a melhoria da saúde. Já G8, gestor de um dos maiores municípios que constituem a UMMES, coloca a preparação de talentos como um dos principais objetivos da gestão. Ele afirma

[...] a segunda área em que nós atuamos, que é o objetivo na nossa gestão, também, é a formação de atletas . É lógico que, quando ele vai chegando no alto nivel, vai ficando dificil para a cidade manter só com o poder público. (G8)

Outro objetivo apresentado por G8 e que foi mencionado apenas por ele é garantir o acesso dos munícipes ao esporte, como se percebe no trecho de sua entrevista destacado abaixo:

[...] eu sempre tenho como objetivo principal dois pontos que eu acho que é de fundamental importância. Primeiro, é a massificação do esporte, dando não só uma iniciação esportiva para as crianças mas um lazer para a população. Essa é uma questão que a gente tem que abranger toda a cidade. (G8)

Dessa forma, este gestor foi o único a apontar um importante objetivo do esporte, que constitui uma quarta categoria: Esporte e democratização do acesso. O esporte é um fenômeno sociocultural que se manifesta de diferentes formas na sociedade. $\mathrm{O}$ acesso ao esporte é um direito social, um direito do cidadão, sendo entendido como um fator de promoção e inclusão social. Por essa razão, ele ocupa um espaço importante na vida da população, sendo disseminado em todas as faixas etárias e extratos sociais. Podemos assim afirmar que o esporte tem grande impacto na sociedade, sendo transformado por ela, ao mesmo tempo em que a transforma.

O esporte como um direito social, é um serviço público indispensável ao munícipe, cabendo aos gestores do esporte atender às necessidades, interesses, motivações desse público. Desta forma, ao pensarmos em políticas públicas de esporte, entendemos que elas devem refletir o programa de governo, a política econômica, social, cultural, bem como suas formas de gestão. Para aperfeiçoar o processo de gestão, é preciso compreender sua realidade e seus desafios atuais.

\section{CONSIDERAÇÕES FINAIS}

Realizamos este estudo com o propósito de caracterizar o perfil dos gestores municipais de esporte de doze cidades pertencentes à UMMES, um consórcio intermunicipal no estado de São Paulo e conhecer seu olhar sobre os objetivos do esporte no município. Acreditamos que, para aperfeiçoar o processo de gestão, é preciso compreender sua realidade e seus desafios atuais enxergando de forma complexa e considerando seu caráter multidisciplinar.

$\mathrm{O}$ perfil dos gestores municipais de esporte identificado se assemelha ao encontrado em estudos já realizados. Assim, a necessidade de garantir maior presença feminina em cargos de gestão e de capacitar melhor os profissionais foi evidenciada. Ainda podemos considerar a existência de uma cultura desvaloriza as competências e habilidades necessárias para uma gestão de esporte inerentes com o predomínio dos gestores em cargos comissionados, muitas vezes selecionados por fazer parte do círculo de amizade do prefeito ou por pertencer a uma determinada corrente partidária, independentemente de sua experiência com o esporte.

A forma como os profissionais são selecionados pode impactar a construção das políticas públicas e se evidencia no olhar dos gestores sobre o esporte, por vezes fundamentado apenas no senso comum. Em suas entrevistas, os gestores declaram que o esporte em seus municípios tem como objetivos contribuir para a inclusão social e melhorar a saúde e a qualidade de vida dos praticantes. Embora o esporte possa contribuir para que tais objetivos sejam atingidos, a participação construção de uma política pública intersetorial, integrando diferentes áreas da gestão, é fundamental. Sem que esta política seja implementada, o esporte continuará sendo utilizado como uma prática assistencialista e pouco eficiente, alimentando discursos que não se concretizam.

Entendemos ser fundamental que pesquisas nesse âmbito tenham continuidade, uma vez que conhecer as realidades de outros municípios possibilitará uma construção de um maior conhecimento que identifique de maneira mais aprofundada e pontual os cenários em que os gestores municipais de esporte se encontram, 


\section{Percepção dos gestores no esporte municipal}

principalmente as questões como formação profissional, atuação e experiência na função e formação continuada considerando as competências e habilidades necessárias para atuação desses profissionais.

Dessa forma, é possível perceber que, mesmo sendo parte de um consórcio, não há um plano comum sobre o esporte. Identificamos, portanto, uma dificuldade de diálogo entre os municípios que compõem a UMMES para a construção de diretrizes comuns. Acreditamos que os motivos que levam a esta dificuldade devem ser alvo de novos estudos.

\section{REFERÊNCIAS}

1. Almeida, M. A. B., \& Gutierrez, G. L. (2013). A interface da esfera civil nas políticas públicas esportivas: uma análise habermasiana. Motrivivência, 41, 57-70.

2. Almeida, M. A. B., Gutierrez, G. L., \& Marques, R. (2012). Qualidade De Vida: definição, conceitos e interfaces com outras áreas de pesquisa. São Paulo. Escola de Artes, Ciências e Humanidades - EACH/USP.

3. Amaral, C. M. dos S. (2014). Gestor de instalações esportivas no município de São Paulo: perfil, formação e desempenho na função (Dissertação de Mestrado). EEFE/USP - Escola de Educação Física e Esporte da Universidade de São Paulo. São Paulo.

4. Amaral, C. M. dos S., \& Bastos, F. da C. (2015). $\mathrm{O}$ gestor esportivo no Brasil: Revisão de publicações no país. Revista Intercontinental de Gestão Desportiva, 5(1), 68-78.

5. Amaral, C. M. dos S., \& Bastos, F. da C. (2016). Perfil do gestor de instalações esportivas no município de São Paulo. Revista de Gestão de Negócios do Esporte - RGNE, 1(1), 50-63.

6. Amaral. C. M. dos S. (2015). O gestor do esporte no Brasil. In: Rocco Júnior, A. J., Amaral, C. M. dos S., Bastos, F. da C., Mazzei, L. C. (Org.). Ensaios sobre Gestão do Esporte: reflexões e contribuições do GEPAE/EEFE-USP. Sarapuí: OJM Casa Editorial.

7. Anchieta, T. (2010). Perfil do gestor desportivo no Amazonas (Dissertação de Mestrado).
Universidade do Porto - Faculdade de Desporto, Universidade do Porto, Porto.

8. Bahia, M. C., \& Lima, P. C. (2011). Acessibilidade e Inclusão Social nas Políticas Públicas de Lazer. In: Soares, Artemis et al. (org.). Diagnóstico do Esporte e Lazer na Região Norte Brasileira - o existente e o necessário. Manaus: Edua.

9. Bastos, F. da C. Barhum, R. A., Alves, M. V., Bastos, E. T., Mattar, M. F., ... Bellangero D. (2006). Perfil do Administrador esportivo de clubes sócio culturais esportivos de São Paulo/Brasil. Revista Mackenzie de Educação Física e Esporte, São Paulo, 5(1), 13-22.

10. Bastos, F. da C., \& Mazzei, L. C. (2012). Gestão do Esporte no Brasil: desafios e perspectivas. In: Mazzei, L. C. \& Bastos, F. da C. (Org.). Gestão do Esporte no Brasil: desafios e perspectivas. São Paulo: Ícone.

11. Brust, C., Baggio, I. C., \& Saldanha Filho, M. F. (2006). Repensar a gestão das políticas públicas de esporte e lazer: o caso de Santa Maria/RS. Motrivivência. 28(27), 179-192.

12. Cárdenas, A. R. (2013). A atuação de gestores esportivos e a formação, relacionada à gestão oferecida em cursos de graduação de educação fisica (Dissertação de Mestrado). Universidade do Estado de Santa Catarina - Centro de Ciências da Administração e Socioeconômicas - Programa de Pós Graduação em Administração, Florianópolis.

13. Cárdenas, A. R., \& Feuerschütte, S. G. (2014). Formação, relacionada à gestão, oferecida em cursos de graduação em Educação Física: um olhar qualitativo sobre currículos, disciplinas e ementas. Pensar a Prática, Goiânia, 17(4), 1-15.

14. Carvalho, M. J., \& Cruz, I. (2007). Mulheres $e$ desporto: declarações e recomendações internacionais. Lisboa: Associação Portuguesa Mulheres e Desporto.

15. Chelladurai, P. (2013). Managing Organizations for Sport and Physical Activity. 4th. ed. Scottsdale, AZ: Holcomb Hathaway Publishers.

16. Costa, C., \& Sarmento, J. (2012) Caracterização do perfil sócio funcional de presidentes de Federações como gestores esportivos no estado do 


\section{Santos, M.; Freire, E.; Bastos, F.; Mazzei, L.}

Pará. Revista Mineira de Educação Física, Edição Especial(1), 1563-1574.

17. Costa, J. C. O. (2012). O Desporto no conselho de Fafe: Associatismo e Política Desportiva Municipal (Dissertação de Mestrado). Faculdade de Desporto da Universidade do Porto, Portugal.

18. Costa, L. G. L., Carvalho, A. S.; \& Santos, R. C. P. (2011). Perfil do gestor esportivo e diagnóstico da estrutura organizacional das Federações Mineiras. Comunicação apresentada no II Congresso ALGEDE, Monterrey, México.

19. Da Mata, A. A. R. (2011). Políticas públicas de esporte e lazer na cidade de João Pessoa/Paraíba: uma análise do ordenamento legal (Dissertação de Mestrado). Centro de Educação da Universidade Federal da Paraíba - PPGE/CE/UFPB, João Pessoa.

20. DaCosta, L.P. (Ed.). (2005). Atlas do esporte no Brasil: atlas do esporte, educação física, atividades físicas de saúde e lazer no Brasil. Rio de Janeiro: Shape.

21. Gómez Tafalla, A., \& Mestre Sancho, J. (2005). La importância del gestor desportivo em el município. Barcelona: INDE Publicaciones.

22. Instituto Brasileiro de Geografia e Estatística (2010). Perfil dos Municípios Brasileiros: gestão pública 2009. Coordenação de população e Indicadores Sociais. Rio de Janeiro: IBGE.

23. Karnas, G. S. (2013). Perfil do Gestor Desportivo dos Municípios do Rio Grande do Sul (Dissertação de Mestrado). Faculdade de Desporto. Universidade do Porto, Porto.

24. Linhales, M. A., Lopes, T. B., Costa, L. \& Lima, C. L. (2008) Esporte e lazer na grande BH: por onde caminham as gestões públicas? In: Isayama; H. F; Linhales, M. A. (Org.). Avaliação de políticas e políticas de avaliação: questões para o esporte e o lazer. Belo Horizonte: Ed. da UFMG.

25. Lopes, T. B., Linhales, M. A., Costa, L. C. L. R., Lima, C. D. M. S., \& Pereira, T. M. (2007). A inclusão social presente nos discursos dos dirigentes municipais de esporte/ lazer da grandeBH. In: Anais do XV Congresso Brasileiro de Ciências do Esporte [e] II Congresso Internacional de Ciências do Esporte / Colégio Brasileiro de Ciências do Esporte: CBCE, Recife.
26. Marchi Júnior, W. (2015). O esporte - em cenall: perspectivas históricas e interpretações conceituais para a construção de um modelo analítico. In: The Journal of the Latin American Socio-Cultural Studies of Sport. Curitiba, 5(1), 4667.

27. Mazzei L. C., \& Bastos F. da C. (Org.). (2012). Gestão do esporte no Brasil: desafios e perspectivas. São Paulo: Ícone.

28. Mazzei, L.C., \& Rocco Junior, A. (2017). Um ensaio sobre a Gestão do Esporte: Um momento para a sua afirmação no Brasil. Revista de Gestão e Negócios do Esporte (RGNE), 2(1), 96-109.

29. Menezes, V. G. (2009). Gestão de Políticas Desportivas Municipais: Análise da Região Metropolitana do Recife-PE, Brasil, no período de 2002-2008 (Tese de Doutorado). Faculdade de Desporto, Universidade do Porto, Porto.

30. Minayo, M. C. (2008). $O$ desafio do conhecimento: pesquisa qualitativa em saúde. 11.ed. São Paulo: Hucitec.

31. Neves, F. W., Moreira, B. D., Cunha, L. C., \& Silva, M. R. S. (2009). Projeto Segundo Tempo: consolidando um modelo de política pública e de esporte. In: Hecktheur, L. F. A. et al. (orgs.). Politicas públicas de esporte e lazer na cidade do Rio Grande. Rio Grande: [s.n.].

32. Parks, J. B., Quaterman, J., \& Thibault, L. (2007). Contemporary Sport Management. Champaign: Human Kinetics.

33. Pires, G., \& Sarmento, J. (2001). Conceito de gestão do desporto: Novos desafios, diferentes soluções. Revista Portuguesa de Ciências do Desporto, 1(1), p. 88-103.

34. Rocha, C. M., \& Bastos, F. da C. (2011). Gestão do Esporte: definindo a área. Revista Brasileira de Educação Física e Esporte, 25(Número especial), 91-103.

35. Saldanha, J. (2006). Os hábitos e os consumos de desporto como contributo para uma gestão desportiva municipal eficaz: Estudo de caso no Concelho de Redondo (Dissertação de Mestrado em Gestão do Desporto). Universidade Técnica de Lisboa. Faculdade de Motricidade Humana, Lisboa. 


\section{Percepção dos gestores no esporte municipal}

36. Shintani, C. E. (2014). Competividade nos contextos urbanos e do new public governance: um estudo em organizações e entidades do esporte em municípios (Dissertação de Mestrado em Administração). Universidade Nove de Julho, São Paulo.

37. Silva, D. C. (2012). Intersetorialidade, descentralização e empreendedorismo na gestão pública de esporte e lazer no Estado do Espírito Santo (Tese de Doutorado). UFES - Universidade Federal de Vitória - Centro de Educação Física e Desportos. Vitória, Espírito Santo.

38. Silva, D. S, Santos, M. I., \& Ávila, M. A. (2013). Intersetorialidade nas políticas públicas de esporte e lazer no município de Ilhéus-BA. Conexões, 11(3), 13-35.

39. Starepravo, F. A. (2011). Políticas públicas de esporte e lazer no Brasil: aproximações, intersecções, rupturas e distanciamentos entre os subcampos político/burocrático científico/acadêmico (Tese Doutorado). Curitiba/Brasil: UFPR.

40. Theodoulides, A., \& Armour, K.M. (2001). Personal, social and moral development through team games: Some critical questions. European Physical Education Review,7(1), 5-23.

41. Tubino, M. J. G. (2010). Estudos brasileiros sobre o esporte: ênfase no esporte-educação. Maringá: EdUEM.

42. Valente, L. (2011). O perfil do gestor desportivo: um estudo nos Centros de Esportes e Lazer na Prefeitura de Manaus (Dissertação de Mestrado Gestão do Desporto). Faculdade de Motricidade Humana - Universidade Técnica de Lisboa, Portugal.

43. Veronez, L. F. C. (2005). Quando o Estado joga a favor do privado: as políticas de esporte após a Constituição de 1988. (Tese de Doutorado). Universidade Estadual de Campinas - Faculdade de Educação Física, Campinas.

44. Vianna, J. A, \& Lovisolo, H. R. (2011). A inclusão social através do esporte: a percepção dos educadores. Revista Brasileira de Educação Física e Esporte. São Paulo, 25(2), 285-296.

45. Zanata, T.C., Freitas, D.M., Carelli, F.G., \& Costa, I.T. (2018). O perfil do gestor esportivo brasileiro: revisão sistemática da literatura. Movimento, 24(1), 291-304.. 